\title{
Quantifying the uncertainties of climate change effects on the storage-yield and performance characteristics of the Pong multi-purpose reservoir, India
}

\author{
B. Soundharajan ${ }^{1}$, A. J. Adeloye ${ }^{1}$, and R. Remesan ${ }^{2}$ \\ ${ }^{1}$ Institute of Infrastructure and Environment, Heriot-Watt University, Edinburgh, UK \\ ${ }^{2}$ Cranfield Water Science Institute, Cranfield University, Bedford, UK \\ Correspondence to: A. J. Adeloye (a.j.adeloye@hw.ac.uk)
}

Received: 11 March 2015 - Accepted: 11 March 2015 - Published: 12 June 2015

\begin{abstract}
Climate change is predicted to affect water resources infrastructure due to its effect on rainfall, temperature and evapotranspiration. However, there are huge uncertainties on both the magnitude and direction of these effects. The Pong reservoir on the Beas River in northern India serves irrigation and hydropower needs. The hydrology of the catchment is highly influenced by Himalayan seasonal snow and glaciers, and Monsoon rainfall; the changing pattern of the latter and the predicted disappearance of the former will have profound effects on the performance of the reservoir. This study employed a Monte-Carlo simulation approach to characterise the uncertainties in the future storage requirements and performance of the reservoir. Using a calibrated rainfall-runoff ( $\mathrm{R}-\mathrm{R}$ ) model, the baseline runoff scenario was first simulated. The R-R inputs (rainfall and temperature) were then perturbed using plausible delta-changes to produce simulated climate change runoff scenarios. Stochastic models of the runoff were developed and used to generate ensembles of both the current and climatechange perturbed future scenarios. The resulting runoff ensembles were used to simulate the behaviour of the reservoir and determine "populations" of reservoir storage capacity and performance characteristics. Comparing these parameters between the current and the perturbed provided the population of climate change effects which was then analysed to determine the uncertainties. The results show that contrary to the usual practice of using single records, there is wide variability in the assessed impacts. This variability or uncertainty will, no doubt, complicate the development of climate change adaptation measures; however, knowledge of its sheer magnitude as demonstrated in this study will help in the formulation of appropriate policy and technical interventions for sustaining and possibly enhancing water security for irrigation and other uses served by Pong reservoir.
\end{abstract}

\section{Introduction}

Climate change is predicted to affect the hydrology of most regions through its influence on temperature, rainfall, evapotranspiration (IPCC, 2007) and ultimately the runoff and performance of water resources infrastructures such as reservoirs. These impacts must be quantified for better planning and operation of water resource systems. This has been attempted using outputs from general circulation models (GCMs) to force catchment hydrological models for the assessment of runoff impacts. The outputs of these hydrological models then form input to water resources simulation models for the purpose of characterising systems per- formance (see e.g. Fowler et al., 2003; Nawaz and Adeloye, 2006). However, as widely recognised (see Raje and Mujumdar, 2010), there are uncertainties in GCMs climate change predictions not only between GCMs but also within GCMs (Peel et al., 2014). The latter relates to the inability of a GCM to produce the same output over different runs, while the former concerns variability in outputs of different GCM experiments caused largely by structural, parametrisation and initialisation differences. To avoid the complications and uncertainties in downscaled GCM climate predictions, change factor (delta perturbation) method is suggested, in which plausible changes in the runoff impacting weather variables such as precipitation and temperature are assumed and the effect 
of this on runoff is simulated using a suitable hydrological model (Anandhi et al., 2011).

However, whether based on downscaled GCMs or delta perturbations, the traditional approach using single traces of both the current and future hydrology fails to recognise that these single traces represent one realisation of the population of possible traces. Thus, any impact estimated using the single traces can only relate to the average impact; no information is available on either the possible range of impacts or the variability (or uncertainties) of the assessed impacts. To be able to provide these answers, the population (or ensemble) of the current and future climate is required. Peel et al. (2014) did this to characterise within-GCM variability by replicating (100 times) GCM-based single runs of current and future climate, using a Monte Carlo simulation approach. These then produced replicates of runoff (current and future), which were then used to force a hydrological model, leading ultimately to the evaluation of uncertainties and variability in runoff and reservoir yields.

This work has characterised the uncertainties in climate change impacts for the Pong reservoir using an approach similar to that described by Peel et al. (2014). However, major differences between the current study and Peel et al. (2014) include that: delta perturbations instead of downscaled GCM climate change scenarios were used; stochastic modelling to derive replicates of runoff used the runoff series directly, rather than the indirect approach by Peel et al. (2014) in which the rainfall and temperature were modelled stochastically; and reservoir impacts analysis is not limited to the yield/storage alone but includes consideration of performance indices.

In the following sections, more details about the adopted methodology are given. These are then followed by the case study after which the results are presented and discussed. The final section contains the conclusions.

\section{Methodology}

The flowchart of the methodology is shown in Fig. 1.

\subsection{HYSIM hydrological model}

HYSIM was used to simulate catchment runoff in the study. HYSIM is a conceptual rainfall-runoff model that has the capability to simulate river basin scale hydrology as described in detail by Manley and WRA (2006). The mandatory minimum input data requirements to run the model are the precipitation, temperature and potential evapotranspiration. Apart from its possible use in modelling the evapotranspiration, the temperature is also required for the modelling of snowmelt and accumulation based on the empirical degree-day approach. HYSIM has been extensively used in several research studies including snowy catchments of the United Kingdom to address climate change impacts issues (Murphy et al., 2006).

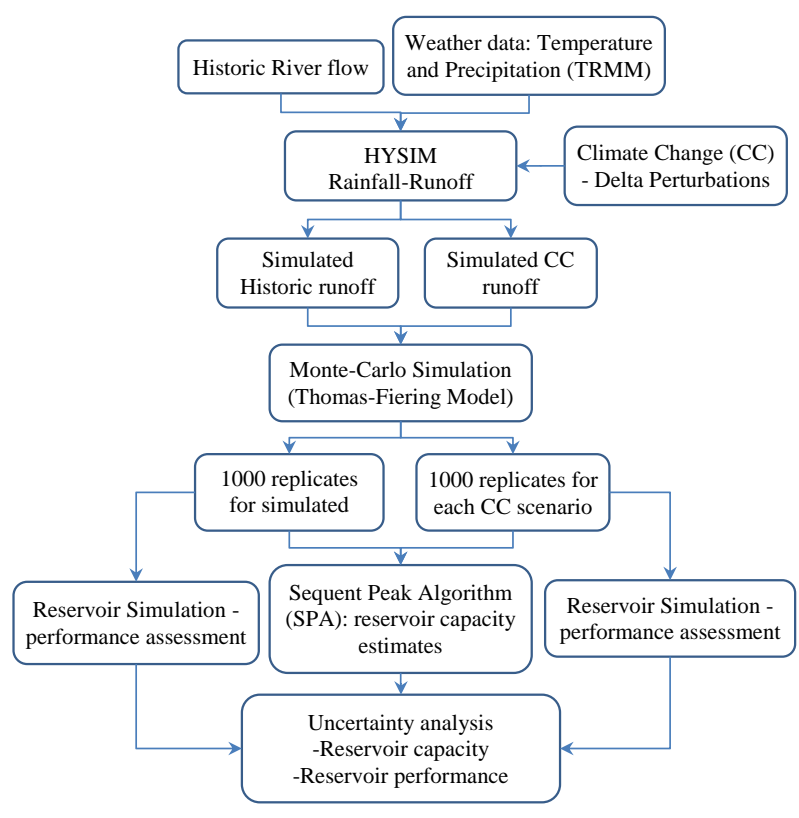

Figure 1. Methodology flow chart.

\subsection{Stochastic data generation}

Replicates of monthly runoff were simulated using the Thomas-Fiering monthly model (McMahon and Mein, 1986):

$$
\left.\begin{array}{l}
Q_{2}=\mu_{\mathrm{Feb}}+b_{\mathrm{Feb} / \mathrm{Jan}}\left(Q_{1}-\mu_{\mathrm{Feb}}\right)+t_{\mathrm{n}} \sigma_{\mathrm{Feb}} \sqrt{\left(1-\rho_{\mathrm{Feb} / \mathrm{Jan}}^{2}\right)} \\
Q_{13}=\mu_{\mathrm{Jan}}+b_{\mathrm{Jan} / \mathrm{Dec}}\left(Q_{12}-\mu_{\mathrm{Jan}}\right)+t_{\mathrm{n}} \sigma_{\mathrm{Jan}} \sqrt{\left(1-\rho_{\mathrm{Jan} / \mathrm{Dec}}^{2}\right)} \\
b_{\mathrm{Feb} / \mathrm{Jan}}=\rho_{\mathrm{Feb} / \mathrm{Jan}} \frac{\sigma_{\mathrm{Feb}}}{\sigma_{\mathrm{Jan}}}
\end{array}\right\}
$$

where, $Q_{1}, Q_{2}$ are generated flows for month January and February respectively; $\mu$ is mean flow for the month indicated; $b$ is least square regression coefficient (Eq. 2); $t_{\mathrm{n}}$ is normal random variate with zero mean and unit variance; $\sigma$ is standard deviation of flow for the month indicated; $\rho$ is correlation coefficient between adjacent months as indicated. Equation (1) assumes that monthly runoff is normally distributed, which as will be seen later is not true for the Beas River. Thus, the Box-Cox transformation (see Eq. 3) was used to normalise the data:

$Q^{\prime}=\left\{\begin{array}{l}\frac{Q^{\lambda}-1}{\lambda}, \lambda \neq 0 \\ \ln Q^{\lambda}=0\end{array}\right.$

where, $Q$ and $Q^{\prime}$ are untransformed (UT) and transformed (Tr) flows respectively, and $\lambda$ is a parameter estimated such that the skewness of $Q^{\prime}$ becomes zero (McMahon and Adeloye, 2005).

After transformation using Eq. (3), the parameters in the Eqs. (1) and (2) are estimated and used for data generation. 
The final step in the data generation is to bring back the generated values to the original values by applying inverse of the Box-Cox transformation:

$$
Q=\left(Q^{\prime} \lambda+1\right)^{1 / \lambda}
$$

\subsection{Sequent Peak Algorithm (SPA) for capacity estimation}

For reservoir capacity estimation, the sequent peak algorithm (SPA) was used (McMahon and Adeloye, 2005):

$$
K_{\mathrm{t}+1}=\max \left(0, K_{\mathrm{t}}+D_{\mathrm{t}}-Q_{\mathrm{t}}\right) ; t \in N
$$

$K_{\mathrm{a}}=\max \left(K_{\mathrm{t}+1}\right)$

where, $K_{\mathrm{a}}$ is reservoir capacity, $K_{\mathrm{t}+1}$ and $K_{\mathrm{t}}$ are respectively the sequential deficits at the end and start of time period $t$, $D_{\mathrm{t}}$ is the demand during $t, Q_{\mathrm{t}}$ is the inflow during $t$ and $N$ is the number of months in the data record. The analysis assumes that the reservoir is full at start and end of the cycle, i.e. $K_{\mathrm{o}}=K_{N}=0$. If $K_{N} \neq 0$, the SPA cycle is repeated by setting $K_{0}=K_{N}$.

\subsection{Reservoir behaviour simulation and performance indices}

To assess reservoir performance, behaviour simulation was carried out using (McMahon and Adeloye, 2005):

$S_{\mathrm{t}+1}=S_{\mathrm{t}}+Q_{\mathrm{t}}-D_{\mathrm{t}}^{\prime} ; \mathrm{LRC} \leq S_{\mathrm{t}+1} \leq \mathrm{URC}$

where, $S_{\mathrm{t}+1}, S_{\mathrm{t}}$ are respectively, reservoir storage at the end and beginning of time period $t ; D_{\mathrm{t}}^{\prime}$ is the actual water released during $t$ (which may be different from the demand $D_{\mathrm{t}}$, depending on the operating rule curves); LRC is the lower rule curve ordinate for the month corresponding to $t$; and URC is the upper rule curve ordinate. Genetic algorithms (GA) optimised rule curves derived for the Pong reservoir by Adeloye et al. (2015) were used.

Following simulation, the performance was summarised using (McMahon and Adeloye, 2005):

Reliability (time-based $\left(R_{\mathrm{t}}\right)$ and volume-based $\left(R_{\mathrm{v}}\right)$ ):

$$
\begin{aligned}
& R_{\mathrm{t}}=N_{\mathrm{s}} / N \\
& R_{\mathrm{v}}=\sum_{\mathrm{t}=1}^{N} D_{\mathrm{t}}^{\prime} / \sum_{\mathrm{t}=1}^{N} D_{\mathrm{t}}
\end{aligned}
$$

Resilience $(\varphi)$ :

$\phi=1 /\left(f_{\mathrm{d}} / f_{\mathrm{s}}\right)=f_{\mathrm{s}} / f_{\mathrm{d}} ; 0<\phi \leq 1$

Vulnerability $(\eta)$ :

$\eta=\sum_{\mathrm{t}=1}^{f_{\mathrm{d}}}\left[\left(D_{\mathrm{t}}-D_{\mathrm{t}}^{\prime}\right) / D_{\mathrm{t}}\right] / f_{\mathrm{d}} ; t \in f_{\mathrm{d}}$ where, $N_{\mathrm{s}}$ is the total number of intervals (months) out of $N$ (months) that the demand was met; $f_{\mathrm{s}}$ is number of continuous sequences of failure periods; $f_{\mathrm{d}}$ is the total duration of the failures; and all other symbols are as defined previously.

\subsection{Pairing of runoff replicates for impact assessment}

To obtain the population of climate change impacts on the various reservoir characteristics, estimates of these characteristics for the current and corresponding future runoff are required. The best way to achieve this is to use a "two-site" stochastic generation approach (see McMahon and Adeloye, 2005), in which the current runoff is a "site" and the future runoff is another "site". This approach was used by Peel et al. (2014) for quantifying the effect on runoff, etc. of climate change perturbations in the precipitation and temperature pair, considering each of these processes as a "site". However, multi-site data generation requires too much effort and can be problematic if the data are non-normally distributed. Consequently, a different approach which is much simpler to use was adopted in this study as follows. After the stochastic generation of 1000 replicates for the current and future runoff, a pair of integer numbers was randomly generated, with the 1st of these representing the current and the 2nd representing the future. This process is repeated until all the 1000 current and future runoff series have been paired up. If during the generation, a number is repeated (i.e. has been generated before), that pair is discarded and a new pair is generated. In this way the current and future hydrology scenarios (or runoff series) are paired up for the purpose of climate change impacts assessment.

\section{Case study river basin and data}

The Beas River, on which the Pong dam and its reservoir are located, is one of the five major rivers of the Indus basin in India (see Fig. 2). The reservoir drains a catchment area of $12561 \mathrm{~km}^{2}$, out of which the permanent snow catchment is $780 \mathrm{~km}^{2}$ (Jain et al., 2007). Active storage capacity of the reservoir is $7290 \mathrm{Mm}^{3}$. Monsoon rainfall between July and September is a major source of water inflow into the reservoir, apart from snow and glacier melt. The reservoir meets irrigation water demands of $7913 \mathrm{Mm}^{3}$ year ${ }^{-1}$ to irrigate 1.6 Mha of command area. The mean monthly distribution of the irrigation releases is shown in Fig. 3. These releases pass through hydropower turbines to generate electricity prior to being diverted to the irrigation fields.

Monthly reservoir inflow and release data from January 2000 to December 2008 (9 years) were available for the study. The historic mean annual runoff (MAR) at the dam site is $8485 \mathrm{Mm}^{3}$ (annual coefficient of variation is 0.225 ). The mean monthly flows are also shown in Fig. 3, which reveals the significantly higher inflows during the Monsoon season. In general, the irrigation demands are larger than the natural river flows except during the Monsoon, implying that such 


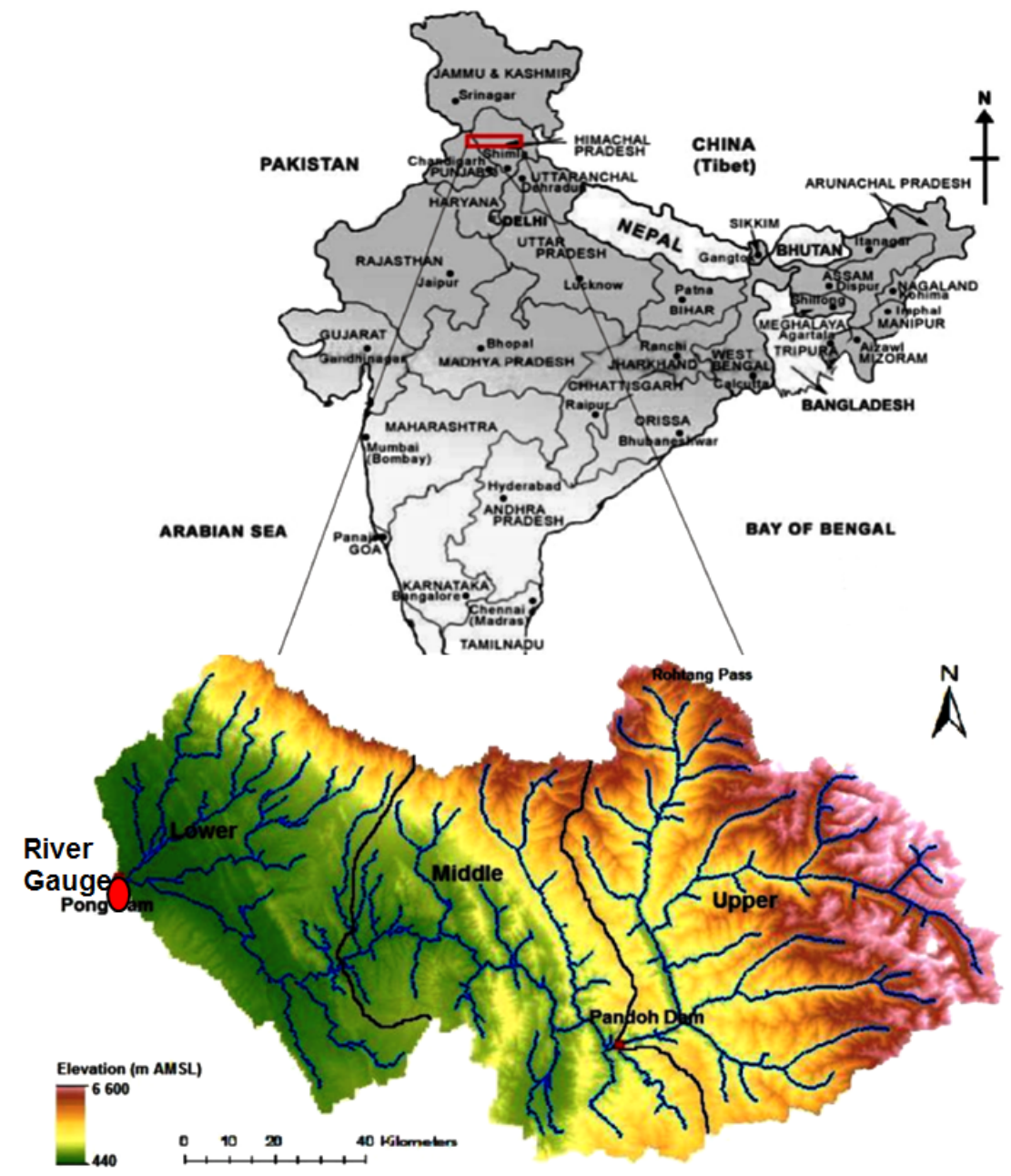

Figure 2. Beas river basin.

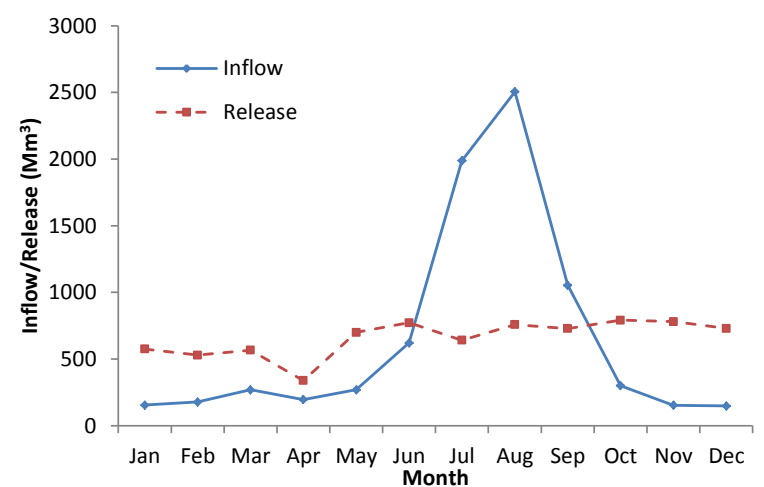

Figure 3. Average monthly inflows and releases from Pong reservoir (2000-2008).

demands cannot be met without the Pong reservoir. Gridded Tropical Rainfall Measuring Mission (TRRM 3B42 V7) daily rainfall data with the spatial resolution of $0.25^{\circ} \times 0.25^{\circ}$ that span the runoff period were used. Since potential evap-
Table 1. Climate change effects on mean annual runoff $\left(\mathrm{Mm}^{3}\right)$. (Values in parenthesis are \% change relative to current conditions.)

\begin{tabular}{lrrr}
\hline$\Delta T,{ }^{\circ} \mathrm{C}$ & \multicolumn{3}{c}{ Annual precipitation change (\%) } \\
\cline { 2 - 4 } & $-5 \%$ & $0 \%$ & $+5 \%$ \\
\hline 0 & 5829.16 & 6217.92 & 6634.23 \\
& $(-6.25)$ & $(0)$ & $(6.70)$ \\
+1 & 6116.36 & 6476.91 & 6853.01 \\
& $(-1.63)$ & $(4.17)$ & $(10.21)$ \\
+2 & 6989.75 & 7349.26 & 7726.83 \\
& $(12.41)$ & $(18.19)$ & $(24.27)$ \\
\hline
\end{tabular}

otranspiration $\left(\mathrm{ET}_{\mathrm{o}}\right)$ measurements were unavailable, estimates were obtained using the Penman-Monteith (P-M) formulation forced with meteorological variables from the NCEP Climate Forecast System Reanalysis (CFSR) data from January 1999-December 2008. 


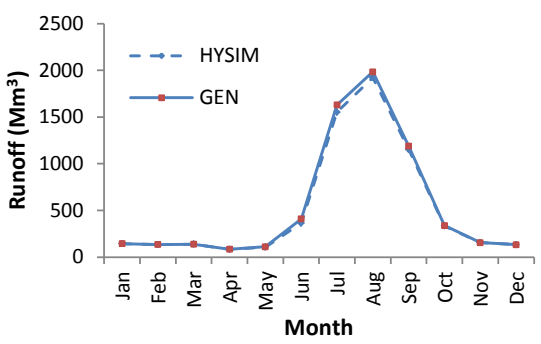

(a)

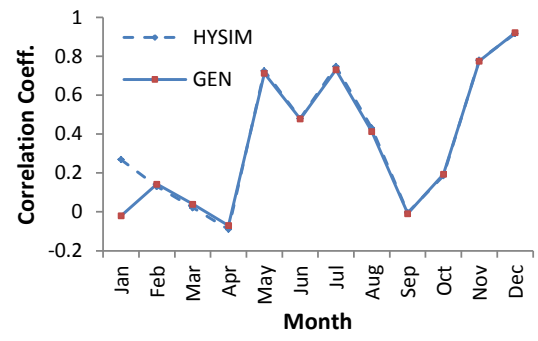

(c)

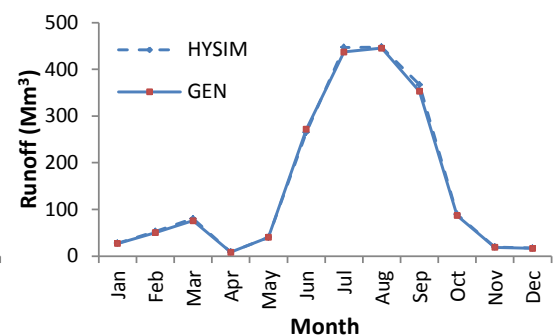

(b)

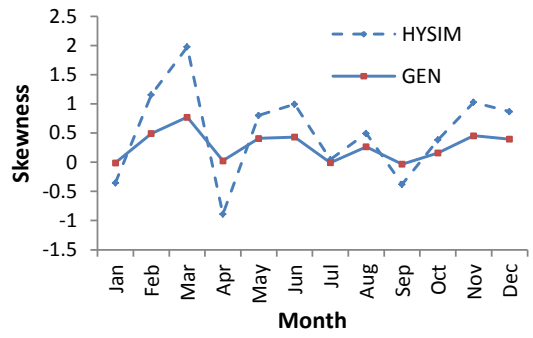

(d)

Figure 4. Comparison of statistics of "observed" (HYSIM) and stochastically generated (GEN) runoff: (a) mean; (b) standard deviation; (c) correlation coefficient; and (d) skewness.

Table 2. Climate change effects on mean seasonal runoff $\left(\mathrm{Mm}^{3}\right)$. (Values in parenthesis are \% change relative to current conditions.)

\begin{tabular}{|c|c|c|c|c|c|c|c|c|c|c|c|c|}
\hline \multirow[t]{3}{*}{$\Delta T,{ }^{\circ} \mathrm{C}$} & \multicolumn{12}{|c|}{ Annual precipitation change (\%) } \\
\hline & \multicolumn{3}{|c|}{ Winter } & \multicolumn{3}{|c|}{ Pre-Monsoon } & \multicolumn{3}{|c|}{ Monsoon } & \multicolumn{3}{|c|}{ Post-Monsoon } \\
\hline & $-5 \%$ & $0 \%$ & $+5 \%$ & $-5 \%$ & $0 \%$ & $+5 \%$ & $-5 \%$ & $0 \%$ & $+5 \%$ & $-5 \%$ & $0 \%$ & $+5 \%$ \\
\hline \multirow[t]{2}{*}{0} & 382 & 410 & 442 & 301 & 327 & 356 & 3594 & 3838 & 4098 & 1550 & 1641 & 1737 \\
\hline & $(-6.8)$ & $(0.0)$ & $(7.8)$ & $(-7.9)$ & $(0.0)$ & $(8.9)$ & $(-6.3)$ & $(0.0)$ & $(6.8)$ & $(-5.5)$ & $(0.0)$ & $(5.83)$ \\
\hline \multirow[t]{2}{*}{+1} & 354 & 376 & 400 & 288 & 308 & 331 & 3877 & 4111 & 4355 & 1595 & 1679 & 1765 \\
\hline & $(-13.5)$ & $(-8.2)$ & $(-2.4)$ & $(-12)$ & $(-5.7)$ & $(1.1)$ & $(1.0)$ & $(7.1)$ & (13.5) & $(-2.8)$ & (2.3) & (7.5) \\
\hline \multirow[t]{2}{*}{+2} & 405 & 426 & 450 & 337 & 359 & 383 & 4414 & 4647 & 4890 & 1832 & 1915 & 2002 \\
\hline & $(-5.9)$ & $(-1.2)$ & (4.0) & (3) & $(9.7)$ & (16.9) & (15) & (21) & (27.4) & (11.6) & (16.7) & $(22.0)$ \\
\hline
\end{tabular}

\section{Results and discussion}

\subsection{HYSIM rainfall-runoff model}

The model was calibrated with daily data from January 2000 to December 2004 and validated using the data from January 2005 to December 2008. In general, the model performed reasonably well with Nash-Sutcliffe efficiency indices during the calibration and validation were respectively 0.88 and 0.78 . The complete details about the performance of the model during calibration and validation are presented by Adeloye et al. (2015).

The calibrated HYSIM model was used to assess impacts of delta changes in the precipitation and temperature on the runoff. Changes in the annual precipitation considered were $\pm 5 \%$ and for temperature, increases of 1 and $2{ }^{\circ} \mathrm{C}$ were considered. The mean values of the simulated annual and seasonal runoff are given in Tables 1 and 2 respectively.
In general, reduction in precipitation causes reduced runoff irrespective of temperature situation. However, the simulation has also revealed the influence of the melting seasonal snow/glacier on the runoff. For example, on an annual scale, increasing the temperature by $2{ }^{\circ} \mathrm{C}$ is causing the runoff to increase by $18 \%$. The effect of decreasing rainfall on the runoff appears moderated by rising temperature due to the resulting runoff from melting snow and glacier. Thus, the $6.3 \%$ reduction in annual runoff arising from a $5 \%$ decrease in rainfall has turned to a $12 \%$ rise in runoff when the temperature rose by $2{ }^{\circ} \mathrm{C}$.

\subsection{Data generation}

The high skew of the untransformed (UT) monthly runoff shown in Table 3 suggests that the monthly runoff cannot justifiably be modelled using the normal distribution. The skew of the Box-Cox transformed data (Tr) are also shown in 
Table 3. Box-Cox transformation parameter $(\lambda)$ and the skew coefficient for untransformed (UT) and transformed (Tr) monthly flow values for current runoff scenario.

\begin{tabular}{lrrrrrrrrrrrr}
\hline & Jan & Feb & Mar & Apr & May & Jun & Jul & Aug & Sep & Oct & Nov & Dec \\
\hline UT & -0.35 & 1.15 & 1.97 & -0.89 & 0.80 & 0.99 & 0.05 & 0.49 & -0.38 & 0.38 & 1.03 & 0.87 \\
Tr & -0.22 & 0.12 & 0.33 & -0.33 & 0.01 & 0.0 & -0.07 & 0.0 & -0.22 & 0.0 & 0.01 & 0.0 \\
$\lambda$ & 2.16 & -1.05 & -1.93 & 0.90 & -0.16 & -0.02 & 0.75 & 0.06 & 1.44 & -0.03 & -2.21 & -1.40 \\
\hline
\end{tabular}

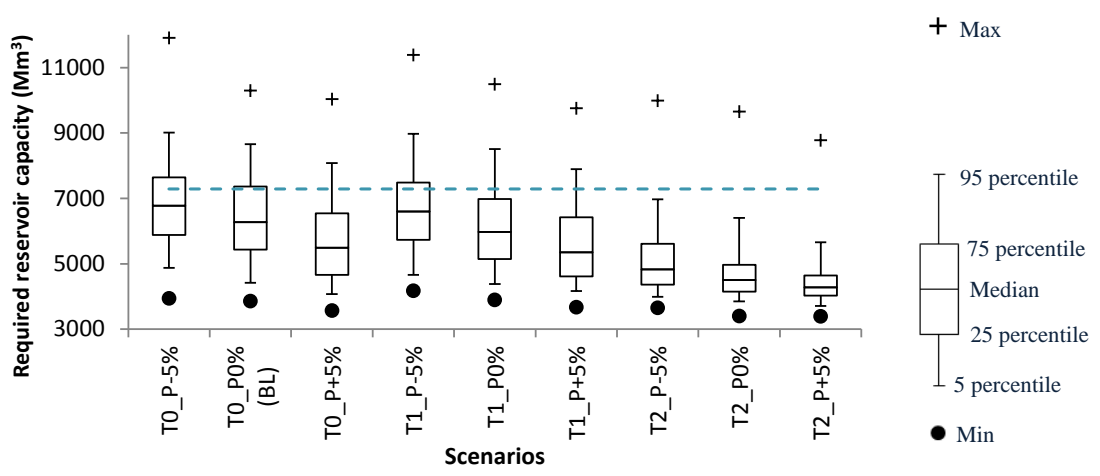

Figure 5. Box plot of reservoir capacity estimates.

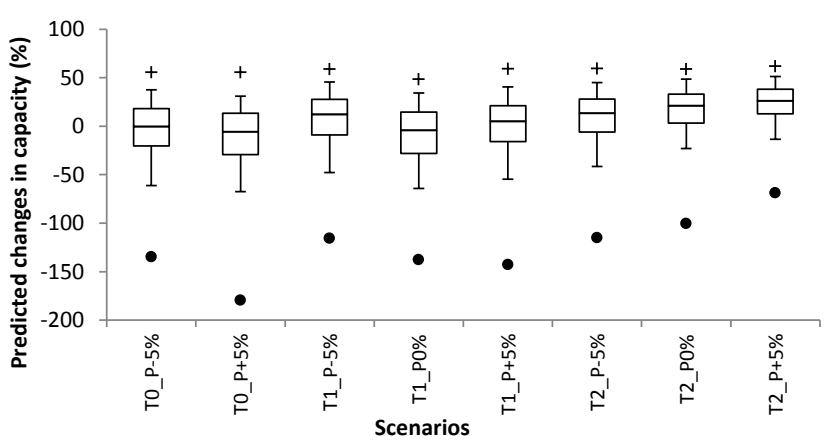

Figure 6. Predicted changes in reservoir capacity (\%)between the current and pertubed (future) scenarios.

Table 3, together with the estimated transformation parameter $(\lambda)$. The transformed data exhibit the required near zero skew.

The characteristics of the generated and historic runoff (current) data are compared in Fig. 4. Similar results are available for the future runoff scenarios but these have been omitted here for lack of space. The generated statistics are the mean over the 1000 replicates. Figure 4 shows the stochastic model has reasonably reproduced the mean, standard deviation and correlation of the historic. The skewness is less well simulated, which is not surprising given that the skew was removed prior to the stochastic modelling. However, this should not be a major concern since reservoir capacity estimate is mostly influenced by the coefficient of variation, $\mathrm{CV}$ (i.e. standard deviation divided by the mean) and less by the skew (Burges and Linsley, 1971).

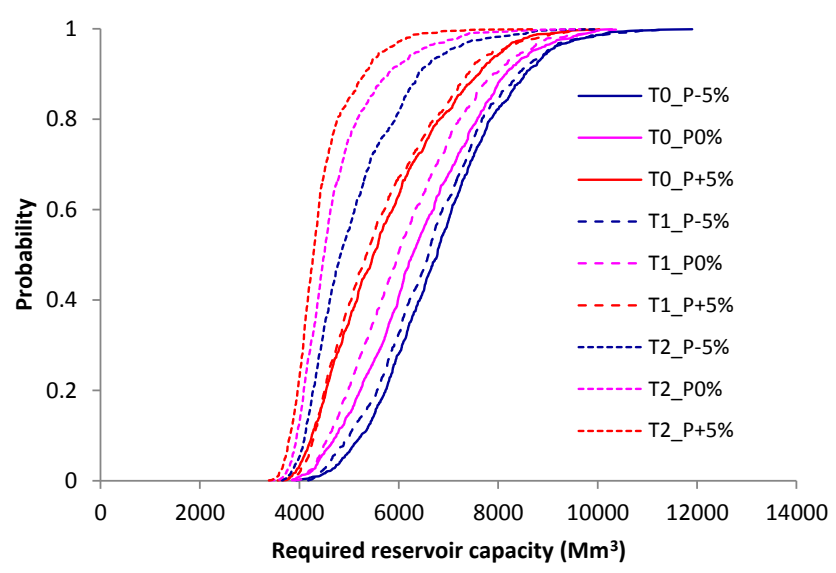

Figure 7. Cumulative distribution function $(\mathrm{CDF})$ of required storage capacity.

\subsection{Uncertainty in capacity estimates}

Population of reservoir capacity based on existing monthly irrigation releases at the Pong (see Fig. 3) are summarised in the box plots in Fig. 5. The horizontal dashed line represents the existing capacity of $7290 \mathrm{Mm}^{3}$. As Fig. 5 clearly shows, there is wide variability in the required reservoir capacity for each runoff scenario. Although the existing capacity of the Pong is $7290 \mathrm{Mm}^{3}$, the required capacity estimates based on the current runoff series could be as low as $3854 \mathrm{Mm}^{3}$ or as high as $10289 \mathrm{Mm}^{3}$. These, respectively, represent overdesign and under-design situations relative to the existing capacity at the Pong reservoir. The implication of under design is that the reservoir will fail frequently to meet the demand, 


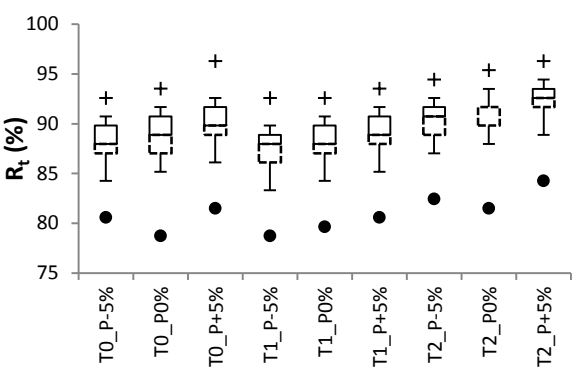

(a)

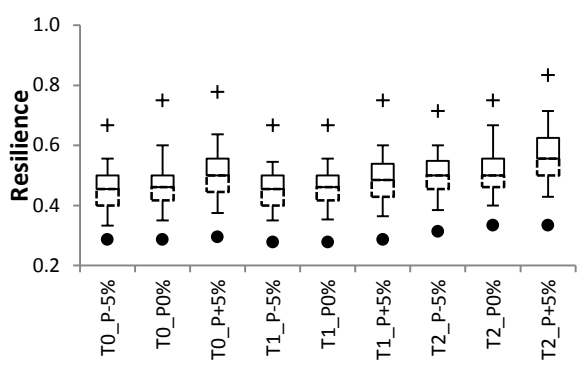

(c)

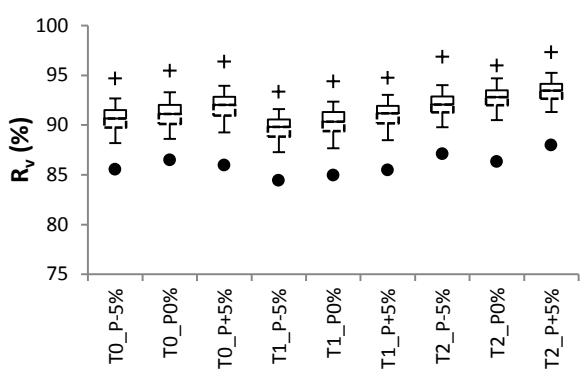

(b)

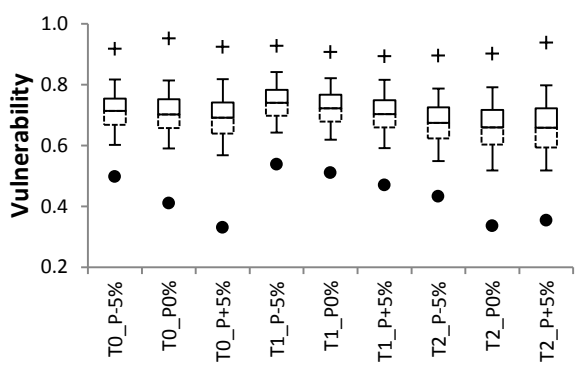

(d)

Figure 8. Box plot of reservoir performance indices: (a) time reliability; (b) volumetric reliability; (c) resilience; and (d) vulnerability.

as recently found by Adeloye et al. (2015), where the simulated vulnerability of the Pong reservoir was shown to be as high as $66 \%$.

The effect of climate change on the capacity estimates broadly follows the effect on runoff. Thus, as the precipitation and hence runoff decreases, the capacity required for meeting the demand increases. Consequently, a $5 \%$ decrease in the rainfall without a change in temperature (T0_P-5\%) would require a capacity as high as $11902 \mathrm{Mm}^{3}$ to meet existing demands. However, when the precipitation increased by the same amount, (T0_P $+5 \%$ ), the maximum capacity was $10029 \mathrm{Mm}^{3}$. This is only marginally less than the maximum capacity for the T0_P0 \% scenario and may be caused by the fact that the additional rainfall especially in the already wet Monsoon season does not influence reservoir capacity estimate. When the precipitation changes are accompanied by increase in temperature, the resulting additional runoff has caused a reduction in the capacity requirement when compared to their corresponding no-temperature change situations.

Figure 6 summarises the population of changes in required reservoir capacity based on the paired experiments discussed earlier. Again, there are huge uncertainties in the predicted changes, which call into question the use of single runs of impact models in water resources climate change impact studies. Figure 6 shows the uncertainties are more pronounced for drier conditions than for wetter conditions. Thus, a $5 \%$ decrease in the rainfall can mean that the current capacity is either too little by as much as $134 \%$ or is too much by $55 \%$. For the most wet future scenario investigated (T2_P $+5 \%$ ), the variability is much less, with either an under design of $68 \%$ or over design of $62 \%$.

The above large arrays of possibilities in the impact of climate change are bound to complicate decision making regarding adaptation and mitigation. Because impacts are not unique, it is obviously misleading to be talking of the impact because such does not exist. However, what can be done is to attach likelihood (or probability) of occurrence to the assessed impacts. Figure 7 shows the empirical cumulative distribution function (CDF) of required capacity estimates for all the investigated scenarios and reveals the rightward shift in the CDF as the catchment becomes drier, implying higher storage requirements at a given probability. Additionally, not only are the drier conditions requiring more storage at a given probability, their CDFs are also less steep resulting in significant differences between the lower and higher quantiles of the capacity estimates.

\subsection{Uncertainty in reservoir performance}

The resulting performance of reservoir behaviour simulation for the ensembles of stochastic replicates generated for various scenarios are shown in Fig. 8a-d. As was the case with the capacity estimates, all the assessed indices have uncertainties. A quick comparison of time based reliability $\left(R_{\mathrm{t}}\right)$ and volumetric reliability $\left(R_{\mathrm{v}}\right)$ shows that $R_{\mathrm{t}}<R_{\mathrm{v}}$. From Fig. $8 \mathrm{a}$, it is evident that, $R_{\mathrm{t}}$ is improving when the precipitation is increasing as expected; similarly temperature increases also improved the $R_{\mathrm{t}}$, due to additional runoff avail- 


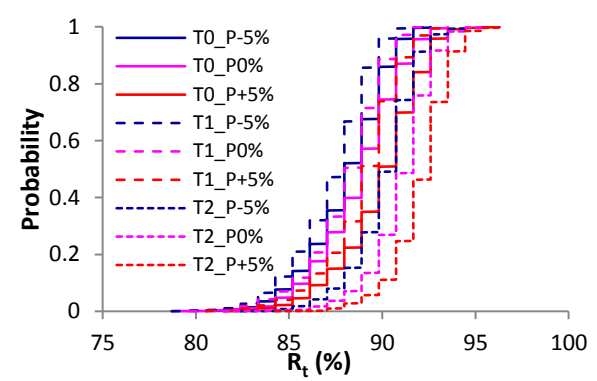

(a)

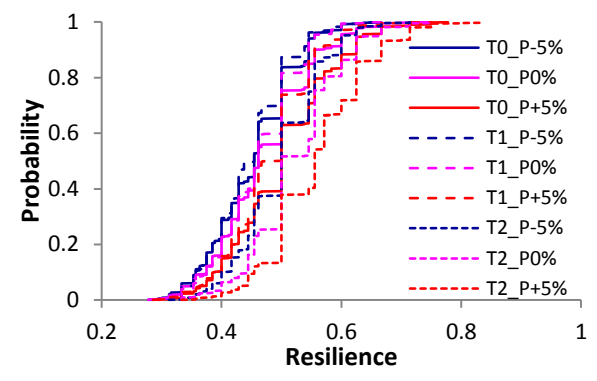

(c)

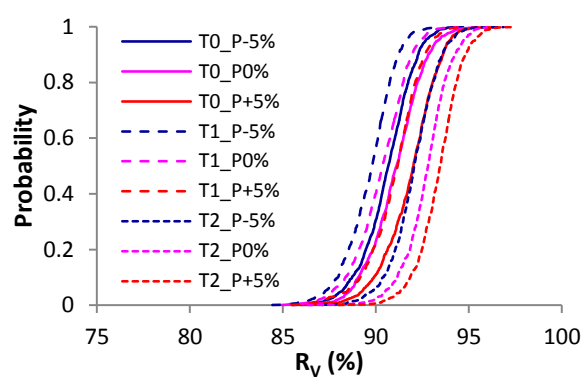

(b)

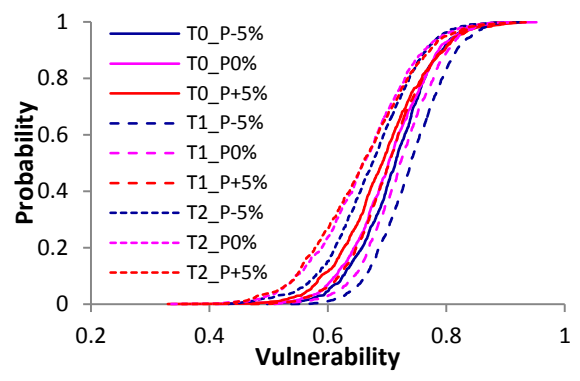

(d)

Figure 9. Cumulative distribution function (CDF) of reservoir performance indices: (a) time reliability; (b) volumetric reliability; (c) resilience; and (d) vulnerability.

ability from snow and glacier melt from the Himalayas. Contrary to $R_{\mathrm{t}}$, the $R_{\mathrm{v}}$ shows less variability for all the scenarios.

Figure $8 \mathrm{c}$ shows the resilience (i.e. probability of recovering from failure) and reveals that, increasing the precipitation also improves the resilience. Figure $8 \mathrm{~d}$ shows the variability in the assessed vulnerability. In general, the vulnerability is decreasing as expected when the precipitation and temperature are increasing. However, although the assessed vulnerability of the Pong reservoir is about $66 \%$ based on single run of the runoff record as alluded to earlier (see Adeloye et al., 2015), the vulnerability could actually be either as low as $33 \%$ or as high as $94 \%$ if the stochastic properties of the runoff are taken into account. In general, vulnerability (or single period deficits) above $25 \%$ is not recommended because of the distress it can cause to water users (Fiering, 1982). Thus, the fact that the least vulnerabilities obtained for the Pong exceeds $25 \%$ requires changes in operational practices, e.g. by hedging, to tamper the large single period shortage. The empirical CDFs of the performance indices are shown in Fig. 9, from where values corresponding to given probability of occurrence can be obtained.

\section{Conclusions}

The Monte Carlo experiments have revealed the limitation of single runoff impact models for water resources impact assessments. The results for the Pong reservoir using delta perturbations in rainfall and temperature have shown that assessed impacts can be highly variable. For example, in re- lation to reservoir capacity needed to maintain existing levels of irrigation water releases, it has been revealed that the needed capacity for future conditions may either be $175 \%$ lower or $60 \%$ higher. The associated reservoir performance indices are similarly highly variable.

Acknowledgements. The work reported here was funded by the UK-NERC (Project NE/1022337/1) - Mitigating Climate Change impacts on India Agriculture through Improved Irrigation Water Management (MICCI) - as part of the UK-India Changing Water Cycle (CWC South Asia) thematic Programme.

\section{References}

Adeloye, A. J, Soundharajan, B., Ojha, C. S. P., and Remesan, R.: Genetic Algorithms optimised hedging rules for improved performance of the Pong Reservoir (India) during scenario-neutral climate change perturbations, Water Resour. Manag., in review, 2015.

Anandhi, A., Frei, A., Pierson, D. C., Schneiderman, E. M., Zion, M. S., Lounsbury, D., and Matonse, A. H.: Examination of change factor methodologies for climate change impact assessment, Water Resour. Res., 47, W03501, doi:10.1029/2010WR009104, 2011.

Burges, S. J. and Linsley, R. K.: Some factors influencing required reservoir storage, Journal Hydraul. Div. ASCE, 97, 977-991, 1971

Fiering, M. B.: Estimates of resilience indices by simulation, Water Resour. Res., 18, 41-50, 1982. 
Fowler, H. J., Kilsby, C. G., and O'Connell, P. E.: Modeling the impacts of climatic change and variability on the reliability, resilience and vulnerability of a water resource system, Water Resour. Res., 39, 1222, doi:10.1029/2002WR001778, 2003.

IPCC, Summary for policymakers, Climate Change 2007: The physical science basis, Contribution of the Working Group I to the Fourth Assessment Report of the Intergovernmental Panel on Climate Change, Cambridge University Press, Cambridge, 18 pp., 2007.

Jain, S. K, Agarwal, P. K., and Singh, V. P.: Hydrology and water resources of India, Springer, the Netherlands, 1258 pp. 2007.

Manley, R. E. and Water Resources Associates (WRA): A guide to using HYSIM, R. E. Manley and water resources associates Ltd, Wallingford, UK, 118 pp., 2006.

McMahon, T. A. and Adeloye, A. J.: Water Resources Yield, Water Resources Publ., Littleton, CO, USA, 220 pp., 2005.

McMahon, T. A. and Mein, R. G.: River and reservoir yield, Water Resources Publ., Col., USA, 368 pp., 1986.
Murphy, C., Fealy, R., Charlton, R., and Sweeney, J. S.: The reliability of an "off the shelf" conceptual rainfall-runoff model for use in climate impact assessment: uncertainty quantification using Latin Hypercube Sampling, Area, 38, 65-78, 2006.

Nawaz, N. R. and Adeloye, A. J.: Monte Carlo assessment of sampling uncertainty of climate change impacts on water resources yield in Yorkshire, England, Climatic Change, 78, 257-292, 2006.

Peel, M. C., Srikanthan, R., McMahon, T. A., and Karoly, D. J.: Uncertainty in runoff based on Global Climate Model precipitation and temperature data - Part 2: Estimation and uncertainty of annual runoff and reservoir yield, Hydrol. Earth Syst. Sci. Discuss., 11, 4579-4638, doi:10.5194/hessd-11-4579-2014, 2014.

Raje, D. and Mujumdar, P. P.: Reservoir performance under uncertainty in hydrologic impacts of climate change, Adv. Water Resour., 33, 312-326, 2010. 